\title{
Arkeolojik Eserlerin Fotogrametri Yöntemi İle 3 Boyutlu Modellenmesi: Demeter Heykeli Örneği
}

\author{
Ahmet USLU ${ }^{1 *}$, Murat UYSAL ${ }^{2}$ \\ ${ }^{1}$ Dumlupınar Üniversitesi, Tavşanlı Meslek Yüksek Okulu, Mimarlık ve Şehir Planlama Bölümü, Kütahya \\ (ahmet.uslu1@dpu.edu.tr) ORCID 0000-0001-8745-423X \\ ${ }^{2}$ Afyon Kocatepe Üniversitesi, Mühendislik Fakültesi, Harita Mühendisliği Bölümü, Afyonkarahisar \\ (muysal@aku.edu.tr) ORCID 0000-0001-5202-4387
}

\begin{abstract}
$\ddot{O} \mathbf{z}$
Uygarlıkların beşiği olarak Anadolu tarih boyunca çok sayıda ve farklı medeniyetlere ev sahipliği yapmış, her döneme ait birçok kültürel ve tarihi mirası üzerinde barından bir toprak parçasıdır. Yüzlerce yıllık bilgi birikimini üzerinde barındıran, gelecek nesillere aktarılması gereken antik eserlerin özüne zarar verilmeksizin dokümantasyonun yapılmasında ve 3B modellerinin üretilmesinde fotogrametri tekniği sıklıkla kullanılmaktadır. Günümüzde fotogrametrik yazılımların gelişimi sayesinde fotoğraflar üzerinden gerçek doku ile kaplanmış 3B modellerin elde edilmesi, model üretimine görsel açıdan bir ivme kazandırmıştır.

$\mathrm{Bu}$ uygulama, Kütahya Arkeoloji Müzesi'nde yer alan Demeter Heykelinin 3 boyutlu modellenmesini içermektedir. Uygulamaya konu olan antik eserin yersel fotogrametrik yöntemle 3 boyutlu modellenmesi için, eser üzerinde işaretlenen kontrol noktaları Focus 6 reflektörsüz totalstation cihazı ile ölçülmüsş ve antik eserin fotoğrafları Nikon Coolpix P510 kamerası ile çekilmiştir. Elde edilen bu veriler PhotoModeler (PM) yazılımında değerlendirilerek belirlenen fotoğraf çiftleri üzerinden $0,5 \mathrm{~mm}$ aralıklı yoğun nokta bulutu ve $\pm 2,39 \mathrm{~cm}$ ortalama konum hassasiyeti ile Demeter Heykelinin 3B modeli üretilmiştir.

Çalışma sonucunda arkeolojik eserlerin korunması ve sonraki nesillere aktarılması için yapılan dokümantasyon çalışmalarında fotogrametrik tekniklerinin kullanılması, bu alanda yapılan işlere doğruluk, hız, maliyet ve ürün çeşitliliği anlamında büyük bir avantaj sağlamakla beraber fotogrametrinin farklı disiplinlere de çözüm sunabileceği görülmüş̧ür.
\end{abstract}

\section{D Modeling Of Archeological Artefacts Using Photogrammetric Method: Demeter Sculpture}

\begin{abstract}
Anatolia is a land which includes various cultural and historical heritage from different ages and it has hosted to humrous different civilization throughout history as a cradle. İn order to make documentation without giving any harm to ancient heritage, to transfer to next generations and produce 3D models, photogrammetric technique is often used. Thanks to the development of photogrammetric software used today, obtaining 3D models covered with real tissue has visually accelerated model production.

This implementation involves 3D modelling of Demeter sculpture in Kütahya Archaeology Museum. For 3D modelling of the relevant antique artefact using ground photogrammetric method, the check-points marked on the artefacts were measured with Focus 6 Reflectorless TotalStation and their photos were taken with Nikon Coolpix P510 camera. The data were analysed using PhotoModeler software and thus 3D models of the
\end{abstract}

* Sorumlu Yazar 
Demeter sculpture were produced with intense dense cloud with $0.5 \mathrm{~mm}$ spacing over specified pairs of photographs and $\pm 2.39 \mathrm{~cm}$ average position accuracy.

As a result of the study, it was seen that in addition to the fact that using ground photogrammetric techniques in documentation of cultural heritage to pass it down to future generations provides a great advantage in terms of accuracy, speed, cost and product variety, photogrammetry can also provide solutions to different disciplines.

Keywords: Archaeological Documentation, Photogrammetry, Point Cloud, 3D Modeling

\section{GIRIS}

Ülkemiz coğrafi konumu itibariyle Asya ve Avrupa kıtalarını birbirine bağlayan köprü vazifesinde olması, göç ve ticaret yollarının üzerinden geçiyor olması, topraklarının verimli ve ikliminin elverişli olması, eşsiz doğal güzelliklere sahip olması gibi nedenlerle zengin kültürlere ev sahipliği yapmıştır. Geçmiş kuşaklar tarafından oluşturulmuş, evrensel değerlere sahip, bütün insanlığın ortak mirası olarak kabul edilen kültür varlıklarını korumak, tanıtımını yapmak, toplumda kültürel mirasa sahip çıkacak bilincin oluşmasını sağlamak, toplumun bilgi ve kültür birikiminin arttırılmasına katkıda bulunmak ve çeşitli etkenlerle tahribata uğrayan, yok olan kültürel değerlerin yaşatılması, dokümantasyonunun yapılması ve gelecek kuşaklara aktarılması için gerekli özverili çalışmaları yapmak bireylere düşen en büyük görevlerdendir (Uslu, 2016).

Kültürel mirasın korunmasina yönelik yapılacak yazılı ve görsel belgeleme çalışmalarında elde edilen bilgilerin, oluşturulan çeşitli ölçek ve nitelikteki çizimlerin koruma ve yaşatma çalışmalarında görev alacak farklı meslek uzmanları tarafından anlaşılır ve kullanılabilir biçimde düzenlenmesi gerekir. Metrik, yazılı ve görsel dokümantasyon, kültürel mirasın mevcut durumu, problemlerinin tespiti ve çözümüne yönelik her türlü koruma çalışmalarında temel altlık olarak kullanılmaktadır (Yakar, 2015).

$\mathrm{Bu}$ noktada fotogrametri tekniği yıllardır arkeolojik ölçmeler, kültürel mirasın dokümantasyonu ve 3B modellenmesi

uygulamlarında hızlı, verimli, ekonomik ve güvenilir bir biçimde veri ve yöntem sağladığı için sıklıkla kullanılmaktadır (Yakar ve Y1lmaz, 2008).

\section{Araștırmanın Amacı}

$\mathrm{Bu}$ çalışmada fotogrametri tekniği ile fotoğraflar üzerinden, yersel lazer tarayıcılar kadar hassas nokta bulutları elde etmeye imkân sağlayan PhotoModeler yazılımı kullanılarak Kütahya Arkeoloji Müzesi'nde sergilenen Demeter Heykelinin düşük maliyette, yüksek çözünürlüğe ve doğruluğa sahip 3B modelinin üretilmesi hedeflenmiştir.

\section{UYGULAMA}

$\mathrm{Bu}$ uygulamada, Kütahya Arkeoloji Müze'sinde yer alan $2.08 \mathrm{~m}$ uzunluğunda ve $610 \mathrm{~kg}$ ağırlığında Demeter Heykelinin 3 boyutlu modellenmesi ele alınmıştır (Şekil 1). Demeter, Yunan mitolojisinde tarımın, bereketin, mevsimlerin ve anne sevgisinin tanrıçasıdır. Homeros'un destanlarında, "güzel saçlı kraliçe" ya da "güzel örgülü Demeter" diye geçmektedir. İnsanlara toprağı ekip biçmesini öğreten bu tanrıçadır. Ekinleri, özellikle de buğdayı simgelemektedir. Hesiodos'a göre Kronos'la Rheia'nın ikinci kızı, ilk tanrı kuşağındandır. Tanrılar tanrısı Zeus'un dördüncü evliliğini onunla yaptığ 1 söylenmektedir. Bu evlilikten de Demeter'in en bilinen çocuğu, yeryüzü ecesi Persephone doğmuştur. Demeter, heykellerinde baygın bakışl1, sağ elinde bir buğday başağ elinde de yanan bir meşale tutan, sarı saçları omzuna dökülen, güzel bir kadın olarak gösterilmektedir (URL-1). 


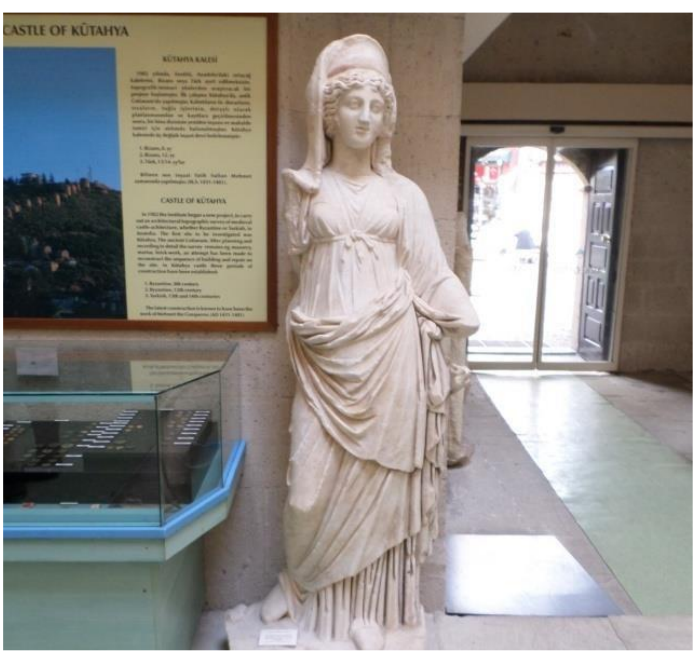

Şekil 1: Demeter Heykeli

Demeter Heykelinin fotogrametrik yöntemle 3 boyutlu modelini elde etme çalışmaları arazi ve büro çalışmaları olmak üzere iki aşamada ele alınmıştır.

\subsection{Arazi Çalışması}

Uygulamanın arazi çalışması aşamasında öncelikle koordinatlandırma ve konum doğruluğunun irdelenmesi amaciyla heykel üzerinde homojen olarak dağılmış 22 adet kontrol noktası belirlenmiştir. Bu noktalardan 14 tanesi üç boyutlu modelin koordinatlandırılması işleminde, 8 tanesi de doğruluk analizinde kullanılmak üzere işaretlenmiştir. Kontrol noktalarının seçiminde heykelin boyutu, müze içerisindeki konumu, yüzeyin fiziksel özellikleri göz önünde bulundurularak keskin hatların seçimine ve kontrol noktalarının fotoğraflarda görünür ve seçilebilir olmasına dikkat edilmiştir. Kontrol noktaları Focus 6 reflektörsüz totalstation cihazı ile lokal koordinat sisteminde ölçülmüştür (Şekil 2). Farklı poligon noktalarından aynı detay noktasına ölçümler yapılarak detay noktalarının kontrolü sağlanmıştır. Uygulamanın ofis çalışmaları kısmında detay noktalarının fotoğraf üzerinde işaretlenmesi, eşleştirilmesi ve koordinatlandırılması işlemlerinde kullanılmak üzere antik eser üzerindeki detay noktalarının krokileri için cephelerin fotoğraflarından yararlanılmıştır (Uysal ve diğ., 2013).

Demeter Heykelinin 23 adet fotoğrafi 16.1 MP çözünürlüğe sahip Nikon Coolpix P510 kamerası ile konvergent çekim esaslarına göre çekilmiştir (Şekil 2). Fotoğraf çekimi yapilırken eserin 3 boyutlu modelinin yüksek çözünürlük ve doğrulukta üretimi için uygun sayıda ve açıda, eser üzerinde işaretlenen her kontrol noktasının dört resimde görünür ve seçilebilir olmasına dikkat edilmiştir. Demeter Heykelinin müzenin iç duvarına sabitlenmiş olması ve müze içerisindeki eserlerin konumlarının birbirlerine çok yakın olması sebebiyle eserin sağ yan yüzeyinin ve arka yüzeyinin fotoğraflarının çekiminde zorluklar yaşanmıştır. Değerlendirme işleminde en uygun olan resimler kullanılmıştır. Kontrol noktalarının ölçümü ve fotoğraf çekimi işlemlerinden sonra elde edilen veriler bilgisayar ortama aktarılarak ofis çalışması aşamasına geçilmiştir.
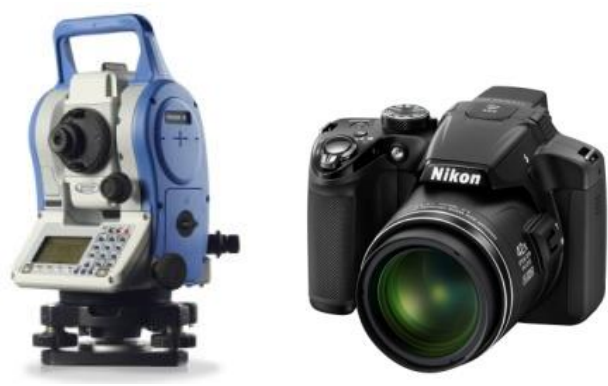

Şekil 2: Focus 6 total station (Sol) ve dijital kamera (Să̆)

\subsection{Ofis Çalışmast}

Değerlendirme işlemleri ve Demeter Heykelinin 3 boyutlu modelini oluşturulma işlemleri için PhotoModeler yazılımı kullanılmıştır. $\mathrm{Bu}$ kapsamda, programa öncelikle kullanılan kameranın iç yöneltme parametreleri yani kamera kalibrasyon değerleri ve değerlendirmede kullanılacak en uygun fotoğrafların girilmesiyle bir proje oluşturularak başlanılmıştır. PhotoModeler yazılımı karşılıklı ve mutlak yöneltme işlemlerini bir arada yaptığ için iki veya daha fazla fotoğrafta görünen 14 adet kontrol noktası nokta atmak suretiyle işaretlenmiştir (Yastıkl1, 2014).

Kontrol noktalarının işaretlenmesinden sonra bir fotoğraf referans alınarak tüm kontrol noktalarının yerleri diğer fotoğraflarda da gösterilerek eşleştirme işlemi yapılmıştır. Daha sonra resim koordinat sisteminden arazi koordinat sistemine dönüşüm için kontrol noktalarının lokal koordinat sistemindeki arazi koordinat değerleri PhotoModeler yazılımının desteklediği bir metin dosyası formatında yazılıma aktarılmıştır (Şekil 3). 


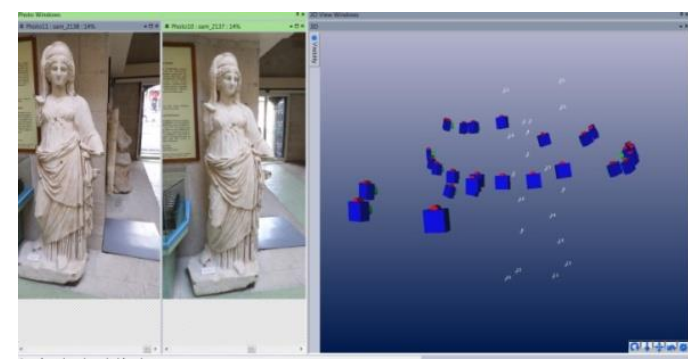

Şekil 3: PM yazılımında resim çekim açıları ve kullanılan kontrol noktaları

Nokta atmak suretiyle eşlenen kontrol noktaları fotoğraf üzerinde seçildikten sonra aynı kontrol noktalarının koordinat tablosundaki karşılıkları seçilerek noktaların üç boyutlu koordinatları sistemde tanımlanmıştır.

PhotoModeler yazılımında demet yöntemine göre yapılan dengeleme işlemi sonucunda projede herhangi bir problemin bulunmadığ dengelemenin başarılı olduğu, yöneltme işleminin yapıldığı ve ortalama nokta işaretleme hassasiyetinin 0.186 piksel olduğu görülmüş̧ür (Şekil 4).

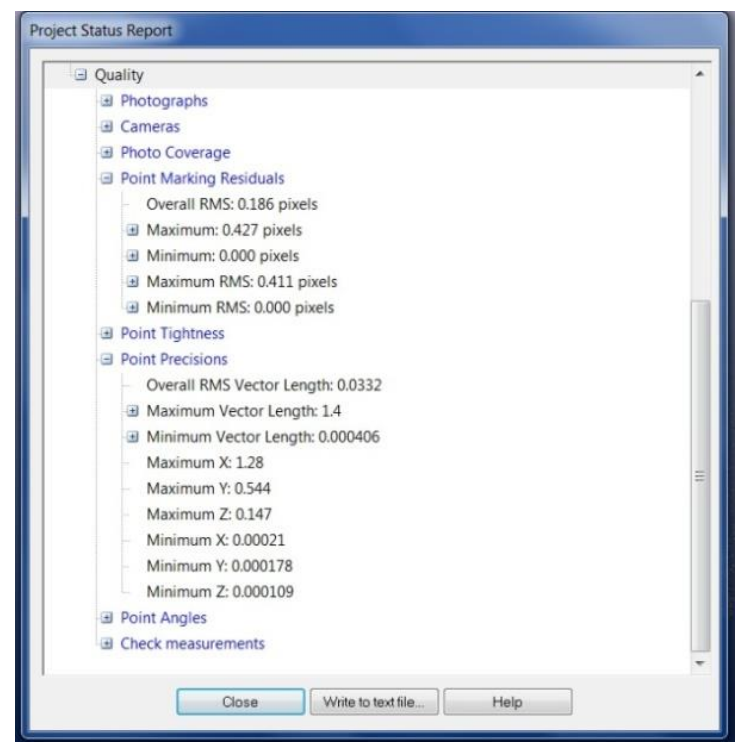

Şekil 4: PM yazılımında dengeleme raporu
$\mathrm{Bu}$ değerler sonucunda yoğun nokta bulutu ve üç boyutlu model üretimi aşamasına geçilmiştir. Nokta bulutu üretimi aşamasında belirlenen fotoğraf çiftlerinden $0.5 \mathrm{~mm}$ sıklıkta yoğun nokta bulutu üretilmiş ve üretilen yoğun nokta bulutu üzerinde bulunan uyuşumsuz noktalar temizlenerek gerekli düzenlemeler yapılmıştır. Elde edilen yoğun nokta bulutuna dengelenmiş olan fotoğraflardan doku kaplaması yapılmış ve yoğun nokta bulutu renklendirilmiştir (Şekil $5)$.

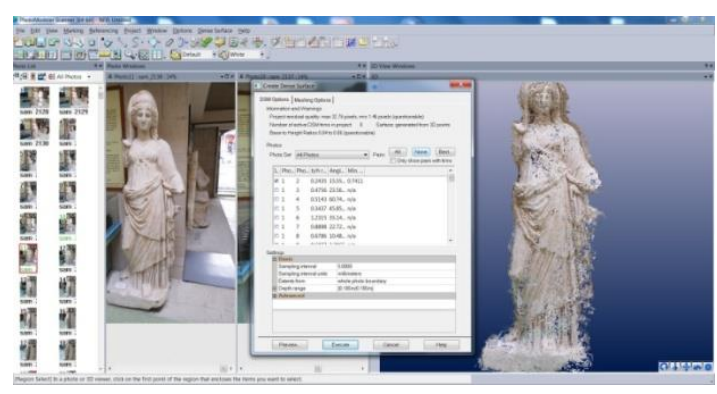

Şekil 5: Modele ait nokta bulutu üretme çalışmaları

Nokta bulutu üretimi sonrasında nokta bulutunun seyreltilmesi, nokta bulutu üretilemeyen alanlarda boşluk doldurma işlemi yapılarak üçgen model elde edilmiştir. Oluşturulan katı model, dengelenmiş fotoğraflardan gerçek dokusuyla kaplanarak Demeter Heykelinin 3 boyutlu modeli elde edilmiştir (Şekil 6). 

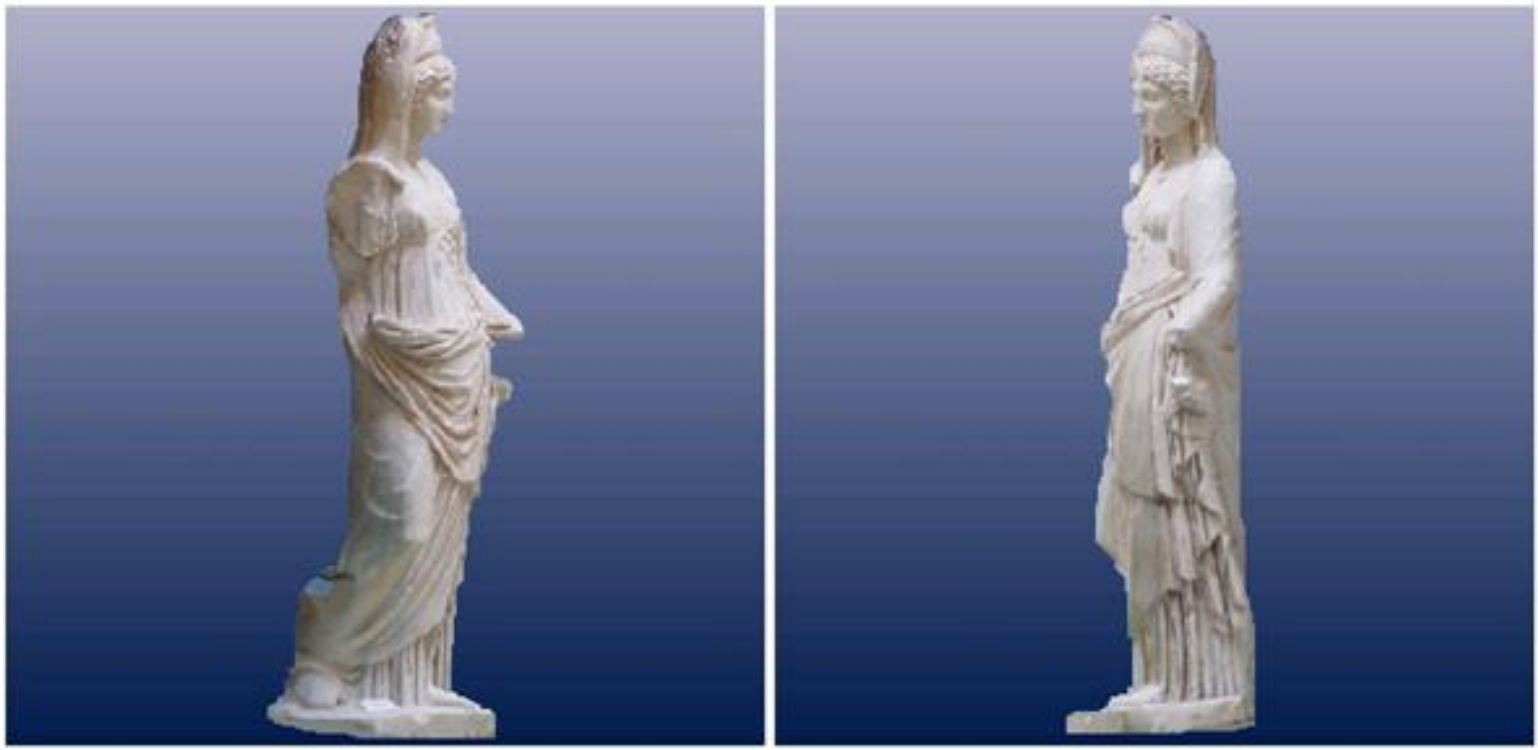

Şekil 6: Heykelin gerçek doku ile kaplanmış 3 boyutlu modeli

\subsection{Doğruluk Analizi}

3 boyutlu modelin hatasinı tespit etmek ve başarısını ortaya koymak için doğruluk analizi yapılmıştır. Doğruluk analizi işlemi araziden elde edilen ve görüntü üzerinden alınan test verilerinin değerlendirilmesi ile sağlanmıştır. 3 boyutlu modelin doğruluğunun analizi için antik eser üzerinde işaretli, koordinatlandırma işleminde kullanılmayan ve homojen olarak dağılmış 8 adet kontrol noktası seçilmiştir. 8 adet kontrol noktası $2.08 \mathrm{~m}$ yüksekliğindeki antik eserin 3 boyutlu modelinin doğruluk analizi için yeterli görülmüştür. Kontrol noktalarının koordinat değerleri elektronik uzaklık ölçer ile hesaplanarak kesin koordinatlar olarak kabul edilmiştir. Aynı kontrol noktalarının resim koordinat değerlerinden farkları hesaplanarak, noktaların $\mathrm{x}, \mathrm{y}, \mathrm{z}$ yönündeki karesel ortalama hataları hesaplanmıştır. Tablo 1 ve Tablo 2'de 3 boyutlu modelin doğruluğunun araştırılması üzerine yapılan çalışmaya ilişsin değerler verilmiştir.

$\mathrm{Bu}$ veriler 1şı ğında 3 boyutlu modelin konum hassasiyeti araştırmasında; $y, x$ ve $z$ koordinatlarında ortalama konum hatas $1 \pm 23,9$ mm olarak bulunmuştur.
Tablo 1. Modele ait kontrol noktalarının koordinat farkları

\begin{tabular}{ccccccc}
\hline & \multicolumn{3}{c}{$\begin{array}{c}\text { Vi Farklar } \\
(\mathbf{m m})\end{array}$} & \multicolumn{3}{c}{$\begin{array}{c}\text { Vi Vi Farklar } \\
\left(\mathbf{m m}^{2}\right)\end{array}$} \\
$\mathbf{N N}$ & $\mathbf{V y}$ & $\mathbf{V x}$ & $\mathbf{V z}$ & $\mathbf{V y ~ V y}$ & $\mathbf{V x ~ V x}$ & $\mathbf{V z ~ V z}$ \\
\hline $\mathbf{1}$ & 18 & 8 & 15 & 324 & 64 & 225 \\
$\mathbf{2}$ & -12 & -14 & 12 & 144 & 196 & 144 \\
$\mathbf{3}$ & -8 & -12 & -16 & 64 & 144 & 256 \\
$\mathbf{4}$ & -17 & -16 & -9 & 289 & 256 & 81 \\
$\mathbf{5}$ & -7 & -11 & -8 & 49 & 121 & 64 \\
$\mathbf{6}$ & 12 & 9 & -13 & 144 & 81 & 169 \\
$\mathbf{7}$ & 16 & -7 & 17 & 256 & 49 & 289 \\
$\mathbf{8}$ & 14 & -15 & 13 & 196 & 225 & 169 \\
\hline
\end{tabular}

Tablo 2. 3B modelin doğruluk analizi sonuçları

\begin{tabular}{cccc}
\hline N.N & \multicolumn{3}{c}{ Vi Farklar $(\mathbf{m m})$} \\
& $\mathbf{V y}$ & $\mathbf{V x}$ & $\mathbf{V z}$ \\
\hline Vmin & 8 & 7 & 8 \\
Vmax & 18 & 16 & 17 \\
Vort & 13 & 11.2 & 12.9 \\
$\mathbf{m}$ & 14.5 & 12.7 & 14.1 \\
$\mathbf{m}_{\mathbf{x y z}}$ & & 23.9 & \\
\hline
\end{tabular}

\section{BULGULAR}

3 boyutlu modelleme uygulamalarının başarısı için aşağıdaki hususların önemli olduğu görülmüştür:

- Modellenecek objenin şekil ve boyutları göz önünde bulundurularak uygun konum ve açıda yeterli sayıda resim çekilmelidir. 
- Jeodezik alım işlemi planlı biçimde yapilmalidir.

- Obje üzerinde işaretlenen kontrol noktalarının uygun biçimde dağılımı, yeterli sayıda olması sonuç ürünü modelin doğruluğunu arttırmaktadır.

- PhotoModeler yazılıminda, 3 boyutlu model oluşturmak konvergent alım yöntemi ile çekilen en az 3 fotoğraf kullanılmalıdır. Fotoğraf sayısının artmasıyla sonuç ürünü modelin doğruluğunun ve çözünürlüğünün arttı̆̆ görülmüştür.

- PhotoModeler yazılımında, fotoğraf çiftlerinde işaretli kontrol noktaları doğru şekilde eşleştirildiğinde $3 \mathrm{~B}$ modelin doğruluğunun arttığ görülmüştür.

- Nokta bulutu üretimi aşamasında, fotoğraflarda nokta bulutunun üretileceği bölge sinırlandırıldığında gereksiz,uyuşumsuz ve bozuk nokta bulutu üretiminin önüne geçilerek, daha kısa sürede nokta bulutunun üretileceği görülmüştür. Yine örnekleme aralığ değeri $10 \mathrm{~mm}$ 'den küçük bir değer seçildiğinde nokta bulutu üretiminde sürenin arttığı ve sik nokta bulutunun oluştuğu görülmüştür.

- PhotoModeler yazılımı model üretimi aşamasında, heykelin alt ve arka yüzeyini oluşturan nokta bulutundaki boşlukların doldurulmasına imkân sağlamıştır.

\section{SONUÇLAR ve TARTIŞMA}

$\mathrm{Bu}$ çalışmada fotogrametrik yöntem ile fotoğraflar üzerinden, yersel lazer tarayıcılar kadar hassas ve sik nokta bulutları üretmeye imkân sağlayan PhotoModeler yazılımından faydalanılarak Kütahya Arkeoloji Müzesi'nde sergilenen Demeter Heykelinin kısa sürede düşük maliyette, yüksek çözünürlük ve doğrulukta 3 boyutlu modeli elde edilmiştir.

Sonuç ürünü 3 boyutlu modelin, arkeolojik dokümantasyon için yüksek doğruluklu çözümler sunduğu ve restorasyon projeleri için de temel altlık olarak kullanılabileceği görülmüştür. Antik eserin amaca uygun ölçekte ayrıntılı cephe çizimleri, çeşitli perspektif çizimleri elde edilebilmektedir. Rölöve restitüsyon ve restorasyon projeleri hazırlanarak Demeter Heykelinin tarihi eser kaçakçıları tarafından tahribata uğramış baş ve kol kısımlarının aslına uygun olarak ihya edilmesi sağlanabilir.

Bilişim teknolojilerinde yaşanan hızlı gelişmeler ile birlikte kültürel mirasın sergilendiği, muhafaza edildiği müzeler de elektronik ortama taşınarak sanal müze veya e-müze olarak adlandırılan yeni bir müze kavramı ortaya çıkmıştır. $\mathrm{Bu}$ noktada fotogrametrik yöntemler kullanılarak elde edilen 3 boyutlu modellerin web tabanl sistemlerle birlikte kullanımı sağlanabilir. Böylece 3 boyutlu modeller doku kaplama özelliğine sahip veri formatlarına dönüştürülerek, kültürel mirasın çağdaş sanal müzecilik anlayışıyla internet üzerinden milyonlarca ziyaretçiye ulaşması sağlanabilir. Çalışma sonucunda çok sayıda medeniyete ev sahipliği yapmış, zengin bir kültür mirasına sahip Kütahya turizmden yeterince pay alamamaktadır. $\mathrm{Bu}$ çalıșma ile Kütahya Müzesi'nin tanıtımına ve turizmine katk1 sağlanmıştır.

\section{KAYNAKÇA}

Uslu, A., (2016). Kültürel Mirasın Üç Boyutlu Modellenmesi ve Web Ortamında Sunulması. Yüksek Lisans Tezi Afyon Kocatepe Üniversitesi Fen Bilimleri Enstitüsü, Afyonkarahisar, 83.

Yakar, M. (2015). Sahip Ata Külliyesi Rölöve Örneği. TMMOB Harita ve Kadastro Mühendisleri Odası 10. Türkiye Harita Bilimsel ve Teknik Kurultayı, Ankara.

Yakar, M., Yılmaz, H.M. (2008). Kültürel Miraslardan Tarihi Horozluhan'ın Fotogrametrik Rölöve Çalışması ve 3 Boyutlu Modellenmesi. S.Ü. Müh.- Mim. Fak. Dergisi C.23 s.2: 25-33.

Uysal, M., Toprak A.S., Polat N., (2013). Afyon Gedik Ahmet Paşa (İmaret) Camisinin Fotogrametrik Yöntemle Üç Boyutlu Modellenmesi, TUFUAB VIII. Teknik Sempozyumu 23-25 Mayıs 2013, KTÜ, Trabzon.

Yastıklı, N. (2014). Yersel Fotogrametrinin Tersine Mühendislik Uygulamalarında Kullanımı. UZAL-CBS Sempozyumu, İstanbul.

(URL 1) www.vikipedia.com. [Ziyaret Tarihi: 10 Ocak 2017]. 